\title{
ENDOCRINE
}

\section{Testosterone Therapy: What We Have Learned From Trials}

\author{
Giovanni Corona, MD, PhD, Luiz Otavio Torres, $\mathrm{MD}^{2}$ and Mario Maggi, MD, $\mathrm{PhD}^{3}$
}

\begin{abstract}
Introduction: The role of testosterone (T) replacement therapy (TRT) in men is still conflicting. In particular, safety concerns and cardiovascular (CV) risk related to TRT have not been completely clarified yet. Similarly, the clear beneficial effects of TRT are far to be established.
\end{abstract}

Aim: To systematically and critically analyze the available literature providing evidence of the benefit-risk ratio derived from TRT in aging men.

Methods: A comprehensive PubMed literature search was performed to collect all trials, either randomized controlled trials (RCTs) or observational studies, evaluating the effects of TRT on different outcomes.

Main Outcome Measure: Whenever possible, data derived from RCTs were compared with those resulting from observational studies. In addition, a discussion of the available meta-analyses has been also provided.

Results: Data derived from RCT and observational studies clearly documented that TRT can improve erectile function and libido as well as other sexual activities in men with hypogonadism (total $\mathrm{T}<12 \mathrm{nM}$ ). Conversely, the effect of TRT on other outcomes, including metabolic, mood, cognition, mobility, and bone, is more conflicting. When hypogonadism is correctly diagnosed and managed, no CV venous thromboembolism or prostate risk is observed.

Clinical Implications: Before prescribing TRT, hypogonadism (total $\mathrm{T}<12 \mathrm{nM}$ ) must be confirmed through an adequate biochemical evaluation. Potential contraindications should be ruled out, and an adequate follow-up after the prescription is mandatory.

Strength \& Limitations: When correctly diagnosed and administered, TRT is safe, and it can improve several aspects of sexual function. However, its role in complicated vasculogenic erectile dysfunction is limited. Conversely, TRT is not recommended for weight reduction and metabolic improvement. Further well-powered studies are advisable to better clarify TRT for long-term CV risk and prostate safety in complicated patients as well as in those curatively treated for prostate cancer.

Conclusion: TRT results in sexual function improvement when men with hypogonadism (total $\mathrm{T}<12 \mathrm{nM}$ ) are considered. Positive data in other outcomes need to be confirmed. Corona G, Torres LO, Maggi M. Testosterone Therapy: What We Have Learned From Trials. J Sex Med 2020;17:447-460.

Copyright (C) 2019, International Society for Sexual Medicine. Published by Elsevier Inc. All rights reserved.

Key Words: Testosterone; Testosterone Replacement Therapy; Sexual Desire; Erectile Dysfunction; Cardiovascular Risk; Prostate Cancer

\section{INTRODUCTION}

Several epidemiological population-based studies have clearly documented an age-dependent decline of testosterone $(\mathrm{T})$ levels

Received July 28, 2019. Accepted November 24, 2019.

'Endocrinology Unit, Medical Department, Azienda Usl, Maggiore-Bellaria Hospital, Bologna, Italy;

${ }^{2}$ Centro Universitário UniBH, Belo Horizonte, Minas Gerais, Brazil;

${ }^{3}$ Sexual Medicine and Andrology Unit, Department of Experimental and Clinical Biomedical Sciences, University of Florence, Florence, Italy

Copyright (c) 2019, International Society for Sexual Medicine. Published by Elsevier Inc. All rights reserved.

https://doi.org/10.1016/j.jsxm.2019.11.270 in men. ${ }^{1}$ However, it has also been documented that associated morbidities influence age-dependent reduction of $\mathrm{T}$ levels, which can be potentially reversible with the improvement of the underlying disorders. ${ }^{2-4}$

In line with the aforementioned considerations, the concept of a functional hypogonadism (HG), in comparison with an organic one, is emerging. ${ }^{5}$ In particular, the latter is an irreversible condition, usually characterized by very low $\mathrm{T}$ levels, due to some organic damage occurring at any level of the hypothalamuspituitary-testis axis, in which the benefit of $\mathrm{T}$ replacement therapy (TRT) is well established. Conversely, functional HG-probably the most common and previously referred as agerelated or late onset $\mathrm{HG}$-is a potentially reversible form, with 
borderline low T levels, mainly associated with sexual symptoms, where the risk/benefit ratio of TRT is more debated. ${ }^{5}$ Lifestyle changes and/or removing the underlying condition is the recommended strategy to increase endogenous T levels. ${ }^{5}$ This position has been recently endorsed by the U.S. Endocrine Society ${ }^{6}$ and, even before, by the Endocrine Society of Australia. Accordingly, the U.S. Food and Drug Administration (FDA) along with Health Canada ${ }^{9}$ recommends TRT only in those subjects with proven "organic" damage of the hypothalamuspituitary-testis axis.

To shed light on the possible benefits of TRT in the aging male, in 2003, the U.S. National Institute on Aging funded a set of clinical trials. Testosterone Trials (TTrials) were then designed and performed as a coordinated set of 7, 52-week randomized placebocontrolled, double-blind trials (RCTs), including 788 men with hypogonadism (TT $<9.4 \mathrm{nM}$ ) older than 65 years (mean age 72 years) treated with $\mathrm{T}$ gel $1 \%$, in the active arm. The results of these studies have been published throughout the last 2 years, providing new evidence on the effects of TRT on aging men. ${ }^{10}$

The aim of this review is to systematically and critically analyze the available literature on the effects of TRT on different outcomes in aging men. In addition, to better clarify the different positions released by medical agencies around the world on this topic, a revision of a worldwide pattern of TRT prescriptions, observed in the last years, is also reported.

\section{METHODS}

The analyses have been conducted based on extensive Medline search for the identification of all trials, either RCTs or observational studies, evaluating the effects of TRT on aging men. The search was conducted including the following keywords ("“testosterone"[MeSH Terms] OR "testosterone”[All Fields]) AND ("therapy"[Subheading] OR "therapy"[All Fields] OR "therapeutics”[MeSH Terms] OR "therapeutics"[All Fields])) AND ("humans"[MeSH Terms] AND English [lang] AND "male"[MeSH Terms]). Publications from January 1, 1969, up to June 1, 2019, were included. When possible, data derived from RCTs were compared with those arising from observational studies. In each section, the results deriving from the TTrials were closely analyzed and discussed. In addition, results from the available meta-analyses were also provided. Meta-analyses have been suggested for addressing questions for which multiple data sources are in conflict or fail to reach a consensus. In addition, meta-analysis evaluation is particularly useful when there are a variety of reports with low statistical power, as pooling data can improve power and provide a convincing result. Finally, a specific section was dedicated to the safety concerns related to TRT.

\section{PATTERN OF T PRESCRIPTION}

T was chemically synthesized for the first time in 1935 simultaneously by Butenandt group in Gottingen and by Ruzicka and Wettstein in Basel. ${ }^{11}$ After its synthesis, T preparations soon became soon for clinical use, first in the form of pellets and then as injectable esters. ${ }^{11}$ Although $\mathrm{T}$ products have been available for almost 80 years, the introduction on the market of more manageable preparations, including gels and long-acting injectable formulations, has dramatically expanded the $T$ business over the last 2 decades. This phenomenon is particularly evident in the United States and Canada, where the possibility to release specific drug- and diseaserelated advertisements has clearly influenced the market. ${ }^{12,13}$ Conversely, during the same period, European $T$ sales remained more stable. ${ }^{12,13}$ Besides the aforementioned pattern, at least 3 large reports, analyzing commercial insurance data, have emphasized a clear misuse of $\mathrm{T}$ prescriptions. In a U.S. claim database survey, Baillargeon et al, ${ }^{14}$ found that among a total of $10,739,815$ men, aged 40 years or older, who were prescribed TRT, between 2001 and 2011, only $74.7 \%$ had their T measured prior to the prescription. Similar data have been reported by Muram et al, ${ }^{15}$ through the analysis of another U.S. Insurance Database. Finally, an evaluation of all outpatient clinics within Veterans Affairs (VA), during fiscal years 2009-2012, of patients who had not previously received TRT and received at least $1 \mathrm{~T}$ dispensing during the study period, showed that only $3.1 \%$ of them underwent an ideal biochemical and clinical evaluation before starting therapy. ${ }^{16}$ Similarly, the same studies have documented that TRT was often prescribed only based on unspecific symptoms including fatigue, weakness and depressed mood, symptoms often present in aging men. ${ }^{12}$

\section{TRT OUTCOMES}

The previous section has clearly illustrated that some form of $\mathrm{T}$ overuse or misuse has been present since 2000 in everyday clinical practice. Whether or not this pattern has influenced claims regarding TRT safety in aging men is still a matter of intense debate. However, it is important to recognize that all available guidelines recommend treating with $\mathrm{T}$ only symptomatic men who present documented reduced $\mathrm{T}$ levels, after appropriate testing. In this section, available evidence of TRT on different outcomes will be provided and analyzed.

\section{Sexual Function}

$\mathrm{T}$ profoundly regulates all aspects of sexual function and, in particular, erectile function and libido. ${ }^{17-19}$ In fact, all available meta-analyses have clearly shown that TRT is effective in restoring sexual desire and libido in men with hypogonadal (total $\mathrm{T}<12 \mathrm{nM} ; 18$ and Table 1). Conversely, no effect was documented when TRT was administered to subjects with normal total T, that is above $12 \mathrm{nM} .{ }^{18}$ Overall, TRT resulted in a mild to moderate effect in the vast majority of the available metaanalyses (Table 1). Sexual effects were proportional to the increase in $\mathrm{T}$ concentration and higher on libido, when compared with erectile dysfunction (ED). A meta-analysis including only RCTs based on the International Index of Erectile Function scoring as the final outcome documented that TRT is able to improve erectile function domain by 2.3 points. ${ }^{20}$ According to Rosen et $\mathrm{al}^{21}$ this increase could be considered 
Table 1. Summary of testosterone replacement therapy (TRT) outcomes

\begin{tabular}{|c|c|c|c|c|}
\hline TRT outcomes & TTtrials & Other RCTs & Observational studies & Meta-analyses \\
\hline \multicolumn{5}{|l|}{ Sexual function } \\
\hline Erectile dysfunction & $\uparrow \oplus \oplus$ & $\uparrow \oplus \oplus$ & $\uparrow \oplus \oplus \oplus$ & $\uparrow \oplus \oplus$ \\
\hline Libido & $\uparrow \oplus \oplus$ & $\uparrow \oplus \oplus \oplus$ & $\uparrow \oplus \oplus \oplus$ & $\uparrow \oplus \oplus \oplus$ \\
\hline Ejaculation & NA & $\uparrow \oplus$ & $\uparrow \oplus \oplus$ & $\uparrow \oplus$ \\
\hline \multicolumn{5}{|l|}{ TRT + PDESi } \\
\hline Erectile dysfunction & NA & $\uparrow \oplus \leftrightarrow$ & $\uparrow \oplus \oplus$ & $\leftrightarrow$ \\
\hline \multicolumn{5}{|l|}{ Body composition } \\
\hline Fat mass & NA & $\downarrow \oplus$ & $\downarrow \oplus \oplus$ & $\downarrow \oplus$ \\
\hline Lean mass & NA & $\uparrow \oplus$ & $\uparrow \oplus \oplus$ & $\uparrow \oplus$ \\
\hline Body mass index & NA & $\downarrow \oplus$ & $\downarrow \oplus \oplus \oplus$ & $\downarrow \oplus$ \\
\hline Weight & NA & $\leftrightarrow$ & $\downarrow \oplus \oplus \oplus$ & $\leftrightarrow$ \\
\hline \multicolumn{5}{|l|}{ Metabolic control } \\
\hline Glucose metabolism & NA & $\uparrow \oplus \leftrightarrow$ & $\uparrow \oplus \oplus \oplus$ & $\uparrow \oplus$ \\
\hline Lipid profile & NA & $\uparrow \oplus \leftrightarrow$ & $\uparrow \oplus \oplus \oplus$ & $\uparrow \oplus \leftrightarrow$ \\
\hline Blood pressure & NA & $\leftrightarrow$ & $\uparrow \oplus \oplus$ & $\leftrightarrow$ \\
\hline \multicolumn{5}{|l|}{ Bone } \\
\hline Bone mass & $\uparrow \oplus$ & $\uparrow \oplus$ & $\uparrow \oplus \oplus$ & $\uparrow \oplus$ \\
\hline Fracture risk & NA & NA & NA & NA \\
\hline \multicolumn{5}{|l|}{ Mood/cognition } \\
\hline Depressive symptoms & $\uparrow \oplus$ & $\uparrow \oplus$ & $\uparrow \oplus \oplus$ & $\uparrow \oplus$ \\
\hline Cognition & $\leftrightarrow$ & $\leftrightarrow$ & $\uparrow \oplus$ & NA \\
\hline \multicolumn{5}{|l|}{ Mobility } \\
\hline & $\uparrow \oplus \leftrightarrow$ & $\uparrow \oplus \leftrightarrow$ & $\uparrow \oplus$ & $\uparrow \oplus$ \\
\hline
\end{tabular}

Arbitrary unit $(\oplus)$ is indicated as follows: $\oplus=$ mild $\oplus \oplus=$ moderate, $\oplus \oplus \oplus=$ strong effect. $\uparrow, \downarrow$, and $\leftrightarrow$ indicate positive effect, negative effect, and neutral effect, respectively.

$\mathrm{NA}=$ not available; PDESi $=$ phosphodiesterase type 5 inhibitor; RCTs $=$ randomized controlled trials; TRT $=$ testosterone replacement therapy; TTrials $=$ testosterone trials.

clinically meaningful only in subjects with mild ED and not in those with more severe forms. Furthermore, it has been reported that a higher prevalence of organic conditions, such as obesity and diabetes, underlining possible vascular damage, attenuated the positive effect of TRT on patients with ED. ${ }^{18,19}$

The aforementioned data are in line with what was derived from the TTrials (Table 1). ${ }^{10}$ Final results showed that TRT, as compared with placebo, increased sexual interest and sexual activity, from flirting to sexual intercourse, with a moderate effect size, which was inversely related to the baseline $\mathrm{T}$ levels and proportional to the increase in $\mathrm{T}$ levels during the study. ${ }^{10} \mathrm{~A}$ greater effect on libido and sexual activity than on erectile function was observed. ${ }^{10}$

Similar data can be derived from observational, open-label surveys, which often report even better outcomes for TRT in improving all aspects of sexual function (Table 1). ${ }^{18,19}$

The data observed for libido and ED are not surprising. In fact, besides hormones, several other factors including psychiatric, relational, or pharmacologic conditions can influence sexual desire, ${ }^{17}$ explaining, at least partially, the limited effects of TRT on libido. In addition, it is important to recognize that the close association between cardiovascular (CV) risk factors and ED can justify the limited role of TRT alone in improving erectile function in more severe forms of ED. The combination of TRT and phosphodiesterase type 5 inhibitor (PDE5i) has been suggested in the latter cases. Only one meta-analysis published so far has investigated this issue. ${ }^{22}$ The data confirmed the possible advantages of using the combined therapy when placebo- and nonplacebo-controlled trials were considered. However, when the analysis was restricted to only placebo-controlled RCTs, the significance of the effect was lost. It is important to recognize that only a limited number of trials were available at that time and that many of them enrolled a mixed population of subjects with eugonadism/hypogonadism. ${ }^{22}$

The possible role of TRT in improving ejaculatory function represents another conflicting issue (Table 1). An association between delayed ejaculation and reduced $\mathrm{T}$ concentrations has been reported, although not confirmed in all studies. ${ }^{18,19}$ Several register observational surveys have documented that TRT can improve orgasmic function. ${ }^{18,19}$ A placebo-controlled RCT specifically evaluating ejaculation together with its specific components, including frequency and force of ejaculation, semen volume, and bother regarding ejaculatory function documented that axillary $\mathrm{T}$ gel $2 \%$ improved all the aforementioned areas, when compared with placebo. ${ }^{23}$ This was confirmed in the metaanalyses specifically evaluating this issue, although only a limited number of studies were available. ${ }^{20,22}$ Hence, although some 
positive evidence suggests that TRT can improve ejaculation and orgasmic function, more placebo-controlled RCTs are advisable to confirm this effect.

\section{Obesity}

A large body of evidence has shown that overweight and obesity represent risk factors for the development of secondary $\mathrm{HG}^{24,25}$ Accordingly, longitudinal data from the European Male Aging Study have shown that obesity at the baseline and weight gain during follow-up increased the risk, whereas subjects who lost weight during the study were more prone to recover from secondary HG. ${ }^{26,27}$ The specific mechanisms underlying obesityassociated HG have not been completely clarified. However, a working hypothesis is that the metabolic derangements associated with obesity can act either at a central or at a peripheral level, inducing the development of mixed or, more frequently, secondary HG. ${ }^{24,28}$ Only few RCTs have specifically evaluated the effect of TRT on obese individuals (Table 1). Fui et $\mathrm{al}^{29}$ showed that in obese men (body mass index $[\mathrm{BMI}] \geq 30 \mathrm{~kg} / \mathrm{m}^{2}$ ) with a repeated total $\mathrm{T}$ concentration $<12 \mathrm{nM}$, receiving a very low-energy diet, TRT is able to improve body composition (reduction of fat mass and increase of lean mass), without any difference in final weight, when compared with placebo. Similar results were derived from a recent meta-analysis investigating the effect of TRT in available placebo-controlled RCTs (Table 1). ${ }^{30}$ Interestingly, the latter meta-analysis documented that TRT caused equal modifications in fat and lean mass, which can explain the lack of change observed in final weight and in the BMI. ${ }^{30}$ The main limitation of the available RCTs is the short duration of the follow-up ( $<3$ years). Hence, possible long-term effects of TRT on body composition are unknown. Data derived from observational and uncontrolled studies, with a longer follow-up, suggest that TRT can eventually induce a reduction of body weight and BMI, after at least 2 years of treatment (Table 1). ${ }^{31}$ However, it is important to recognize that uncontrolled studies present important limitations because residual confounding factors may represent a source of selection bias in accordance with the nonrandom assignment of T exposure. In fact, physicians often prefer to treat healthier individuals, and healthier individuals more often request treatment for their HG-related problems, thus accounting for better outcomes in this group.

Meta-analyses of available evidence clearly documented that weight loss, however obtained (low calorie diet or bariatric surgery), and/or physical activity are able to improve $T$ concentrations and to revert obesity-associated HG. ${ }^{32}$ Hence, lifestyle modifications should be the first approach for improving body composition and for increasing $\mathrm{T}$ levels in obese individuals. However, the magnitude of $\mathrm{T}$ increase after lifestyle modifications is rather modest (about 2 nmoles/L; 32). Furthermore, therapeutic diets and behavioral modifications - although reasonable strategies for protecting against obesity-associated HG-often fail, and a large proportion of subjects regain weight during follow-up. In addition, an open question is whether obese, individuals with hypogonadism individuals have the skills to progress safely and effectively along the continuum of changing their lifestyle. For instance, physical limitations, including reduced muscle mass and increased fat mass, might limit their propensity to increase physical activity. It is therefore conceivable that a short-term TRT trial, by improving muscle mass, will help obese patients with HG to overcome their overfed, inactive state to become physically and psychologically ready for changing their lifestyle. On the other hand, a combined approach with a controlled dieting program and TRT might result in a better outcome. Accordingly, by combining the available evidence with a meta-analytic approach, we previously reported that TRT might result in better outcomes when compared with lifestyle modification alone. ${ }^{33}$ However, it should be recognized that the number of the available trials, and the related amount of patients enrolled, is too limited to draw conclusions.

\section{Metabolic Syndrome and/or Type 2 Diabetes}

The role of TRT in improving metabolic derangements occurring in type 2 diabetes (T2DM) and metabolic syndrome (MetS) is conflicting. Only limited numbers of placebocontrolled RCTs have specifically investigated the effect of TRT in these populations (Table 1). TIMES-2, the largest study performed in either T2DM or MetS subjects $(\mathrm{n}=220)$ was not able to document a significant reduction in $\mathrm{HbA} 1$ concentrations or the BMI after 26 weeks of $\mathrm{T}$ gel $1 \%$, although an improvement in Homeostatic Model Assessment of Insulin Resistance was reported. ${ }^{34}$ This was confirmed even when only patients with T2DM were analyzed. ${ }^{34}$ The largest RCT conducted only on T2DM is the BLAST (an acronym taken from the UK cities and towns of Birmingham, Lichfield, Atherstone, Sutton Coldfield, and Tamworth) study, which included 199 men recruited from 7 UK diabetes registers. ${ }^{35}$ After 30 weeks, long-acting injectable testosterone undecanoate (TU) resulted in a significant improvement of $\mathrm{HbAl}$ concentrations, particularly in poorly controlled men (baseline $\mathrm{HbAlc} \geq 58 \mathrm{mmol} / \mathrm{mol} ; 7.5 \%$ ) and a decrease in waist circumference, without any significant modification in the BMI. ${ }^{35}$ In contrast to these observations, Gianatti et $\mathrm{al}^{36}$ did not observe any improvement in $\mathrm{HbA1}$ concentrations or the Homeostatic Model Assessment of Insulin Resistance index in 88 men with T2DM after 40 weeks of longacting injectable TU, when compared with placebo. However, as reported in the general population, ${ }^{30}$ an improvement in body composition (reduction of fat mass and increase in lean mass) was documented in the active arm. ${ }^{36}$ Similar considerations can be derived from available meta-analyses, which documented a limited improvement of fasting glycemia and insulin resistance, with even poorer results when only high-quality trials were considered (Table 1). ${ }^{37}$

Long-term registry studies have shown that TRT might improve glycometabolic control in men with T2DM and MetS, up to 8 years (Table 1). ${ }^{38-41}$ The results of these studies present important limitations, as reported previously. However, it should be recognized that the longer follow-up and the differences in the 
characteristics of the subjects treated in the observational studies could explain, at least partially, the difference observed when compared with placebo-controlled RTCs. ${ }^{31}$ Despite these considerations, present evidence suggests that possible contributions of TRT on glycometabolic outcomes are limited, and TRT cannot be suggested as an alternative treatment for T2DM or MetS.

The effects of TRT on other parameters of MetS such as lipid profile and blood pressure are even more conflicting, and the available evidence is too limited to draw any conclusions (Table 1).

\section{Bone}

Much evidence has documented that bone health requires circulating sex steroids within the normal range. ${ }^{42} \mathrm{~T}$ concentrations can differentially interfere with bone homeostasis and the risk of osteoporosis. The possible association between mild HG and osteopenia/osteoporosis is weak, whereas severe HG (total $\mathrm{T}<3.5 \mathrm{nM}$ ) is frequently associated with bone loss and osteoporosis, independently from the patient's age. ${ }^{42} 2$ independent meta-analyses showed a positive effect of TRT on bone mineral density (BMD), with a higher effect at the lumber level. ${ }^{43,44}$ Similarly, data derived from the TTrials confirmed that TRT increased BMD in aging men with hypogonadism particularly at the spine level. ${ }^{10}$ Insufficient data have been published to calculate the effect of TRT on the risk of bone fractures. ${ }^{42}$ In addition, the contribution of TRT on top of antiresorptive treatments in patients with hypogonadism patients at a high risk of fractures has not been established. Hence, antiresorptive therapy must be the first choice of treatment in men with hypogonadism at high risk for bone fracture. The combination with TRT should be offered in the presence of HG-related symptoms.

\section{Mood}

Several observational studies have documented a relationship between depressive symptoms and reduced $\mathrm{T}$ concentrations. ${ }^{45}$ The specific relationship between HG and the incidence of clinical depression are still unclear. ${ }^{45}$ Data derived from the TTrials showed that TRT modestly improved mood and depressive symptoms, using several instruments. ${ }^{10}$ In line with these data, the largest meta-analysis published so far, including 1890 men with HG (baseline total $\mathrm{T}<12 \mathrm{nmol} / \mathrm{L}$ or $\mathrm{fT}<225$ $\mathrm{pmol} / \mathrm{L}$ ) from $27 \mathrm{RCTs}$, documented that a positive effect of TRT on depression was particularly evident only in patients with milder symptoms. ${ }^{46}$ Information regarding the combination between an established depressive therapy and TRT is unknown.

\section{Cognition}

Reduced $\mathrm{T}$ levels have been associated with a precocious cognitive impairment in subjects treated with androgen deprivation therapy for prostate cancer $(\mathrm{PC})^{47}$ and in individuals from the general population. ${ }^{48}$ Despite this evidence, however, the role of TRT in patients with cognitive impairment is still conflicting. Among the TTrials, the Cognitive Function Trial was aimed at assessing the possible improvement of several aspects of cognitive function in 493 individuals with age-associated memory impairment. The trial failed to demonstrate any effect of TRT on improving cognitive function, as assessed by a wide range of tests. ${ }^{10}$

\section{Mobility}

$\mathrm{T}$ has been able to increase muscle growth and strength in several experimental models. Taking advantage of this anabolic effect, androgenic steroids have been used for increasing physical performance in an abusive way in several sport competitions. ${ }^{49}$ Despite this evidence, the role of TRT in older men with mobility limitations remains unclear. Steeves et $\mathrm{al}^{50}$ were unable to detect any association between overall circulating $\mathrm{T}$ levels and the amount of physical activity using data from men enrolled in the National Health and Nutrition Examination Survey, a series of studies designed to assess the health and nutritional status of adults and children in the United States. ${ }^{50}$ Similarly, the Physical Function and Vitality Trials from the TTrials indicated that TRT did not substantially result in any improvement on several physical vitality tests, including the fraction of men whose distance walked in 6 minutes increased more than $50 \mathrm{~m}$ or the absolute increase in the distance walked. ${ }^{10}$ However, when the whole population of the TTrials was considered, a significant, although modest, positive effect on these 2 parameters was reported. ${ }^{10}$ Similarly, a previous meta-analysis of the available data documented only dominant knee extension and dominant handgrip, which showed a tendency toward improvement with T over placebo. ${ }^{43}$ Hence, TRT should not be used to improve mobility in aging men.

\section{Role of TRT in Specific Subpopulations}

Several chronic unhealthy conditions have been associated with reduced T levels. A limited number of RCTs have assessed a possible role of TRT in populations with these conditions. This aspect represents the main limitation for a critical evaluation. In addition, the population included in the few available RCTs is often made up of a combination of men with hypogonadism and men with eugonadism representing another crucial limitation in data analysis. Hence, available evidence does not suggest using TRT to improve mortality or morbidity in these populations (refer the following section).

\section{Subjects with HIV Infections}

HIV-1 infection, and in particular wasting syndrome, is frequently associated with a reduced $T$ concentration. In addition, men infected with HIV often show a premature decline of serum $\mathrm{T}$, associated with inappropriately low/normal luteinizing hormone level and with increased visceral fat. ${ }^{51}$ Fortunately, the era of antiretroviral therapy has dramatically reduced the occurrence of wasting syndrome. Nonetheless, chronic involuntary weight loss remains a serious problem in subjects with HIV. Johns et $\mathrm{al}^{52}$ published the first meta-analysis of the available 4 RCT studies comparing the use of anabolic steroids vs placebo for treating weight loss in adult men and women infected with HIV. They 
showed that anabolic steroids resulted in a small increase in both lean body mass and body weight. We reported an updated metaanalysis on the same topic, confirming the positive result on lean mass. ${ }^{53}$ These data were confirmed in a more recent meta-analysis on the same topic, which included 14 eligible studies. ${ }^{54}$

The main limitations related to the published meta-analyses on this topic are the limited number of available placebo-controlled RCTs and the high heterogeneity among the different studies.

\section{Opioid-Treated Subjects}

The association between reduced $\mathrm{T}$ concentrations, androgen deficiency, and opioid treatment has been documented since the 1970 s, when reports emerged in men who were on maintenance methadone therapy. ${ }^{55}$ Available studies evaluating the impact of opioid treatment on $\mathrm{T}$ concentrations in men with chronic noncancer pain show that the prevalence of opioid-induced androgen deficiency ranges from $19 \%$ to $86 \%$, depending on the considered $\mathrm{T}$ threshold. ${ }^{55}$ Discontinuing opioids may be an option for symptomatic men with reduced $\mathrm{T}$ concentrations. If pain relief with nonopioids is inadequate, or patients are unable to discontinue opioid treatment, TRT should be considered. A limited number of studies have evaluated the effects of TRT on men with opioidinduced androgen deficiency. In the only placebo-controlled RCT available, TRT reduced mechanical hyperalgesia and improved sexual desire and overall quality of life. ${ }^{56}$ The improvement of sexual function and pain relief after TRT has been confirmed in other prospective and retrospective observational trials. ${ }^{55}$

\section{Long-Term Glucocorticoid Therapy-Treated Subjects}

Long-term glucocorticoid (GC) therapy is the most common cause of iatrogenic osteoporosis, accounting for $30 \%-50 \%$ of bone fractures. GC treatment is frequently associated with male HG by inhibiting the secretion of gonadotropins and by inhibiting Leydig cell function. ${ }^{53}$ Adult men on GC who develop HG should theoretically benefit from TRT. However, limited information is available. In the first placebo-controlled RCT, involving 51 men on a mean daily prednisone dose of $12.6 \pm 2.2 \mathrm{mg}$, TRT increased muscle mass, muscle strength, and lumbar spine BMD after 12 months. ${ }^{57}$ Similar results were previously reported in a non-placebo-controlled RCT dealing with GC-treated asthmatic men. ${ }^{58}$

\section{Chronic Obstructive Pulmonary Disease}

Chronic obstructive pulmonary disease (COPD) represents another chronic condition frequently associated with male HG. ${ }^{53}$ An available meta-analysis, including only 9 observational studies and 2,918 men with COPD, concluded that TRT did not improve exercise capacity outcomes, including peak muscle strength and peak workload. ${ }^{59}$ Limited evidence for improving lean mass in men with COPD and hypogonadism treated with TRT has been reported. ${ }^{53}$ However, the vast majority of the interventional trials evaluating the effect of TRT in this population are nonplacebocontrolled trials, further limiting the evidence.

\section{Chronic Kidney Diseases}

Impaired renal function in chronic kidney diseases, and, in particular, in end-stage renal diseases is frequently associated with male HG. ${ }^{53}$ Some prospective studies have documented that a low level of $\mathrm{T}$ can be considered an independent risk factor for the progression of the disease and for overall mortality in this population. ${ }^{60}$ However, placebo-controlled RCTs specifically evaluating the effect of TRT in subjects with chronic kidney disease or end-stage renal disease are lacking.

\section{Inflammatory Bowel Diseases}

Data derived from an animal model and clinical observational studies have suggested a possible anti-inflammatory effect of TRT. ${ }^{61,62}$ Some registered studies have documented that normalization of $\mathrm{T}$ concentrations in men with hypogonadism with Crohn's disease might have a positive effect on the clinical course of the diseases, also evidenced by the improvement of some biochemical parameters. ${ }^{63,64}$ No RCTs specifically evaluating the effect of TRT in patients with inflammatory bowel diseases are available so far. In addition, data derived from observational studies have not been replicated by other groups. ${ }^{53}$

\section{SAFETY}

Safety concerns remain one of the most conflicting issues related to TRT in age-related or functional HG. In particular, CV safety, as well as prostate safety, still represents hot and not completely clarified topics. The evidence related to these subjects will be analyzed in detail in the section "Cardiovascular Safety."

\section{Cardiovascular Safety}

Few studies (one RCT, 2 observational surveys, and one metaanalysis) published between 2010 and 2014 created a great claim in the scientific community, emphasizing a possible increased CV risk related to TRT. ${ }^{65-68}$ These studies present important limitations already recognized elsewhere. ${ }^{69-71}$ However, taking into consideration the results of these studies, in 2015, the FDA issued a safety notification regarding the misuse of $\mathrm{T}$-containing products, due to a potential CV and thromboembolic risk. ${ }^{8}$ Soon after, similar considerations were released by Health Canada. ${ }^{9}$ Conversely, the European Medical Agency did not share the FDA's opinion of an increased $\mathrm{CV}$ risk linked to $\mathrm{T}$ medication because of the lack of convincing evidence. ${ }^{65}$ These contradictory positions deserve further consideration.

\section{Overall CV Risk}

The first study suggesting a possible increased CV risk related to TRT was the "Testosterone in Older Men with Mobility Limitations" (TOM) trial, a double-blind placebo-controlled RCT aimed at evaluating possible improvements in several mobility outcomes among more than 200 men with hypogonadism with mobility limitations. ${ }^{65}$ The study was prematurely interrupted beause of higher CV-related events in the 
active arm. However, several limitations have been recognized. The population enrolled was based on a large group of men with a high prevalence of associated morbidities that were treated with a supraphysiological dose of $\mathrm{T}$ gel (100 mg daily). In addition, $\mathrm{CV}$ events were not adjudicated. In addition, several minor CV problems, including self-reported syncope and peripheral edema, were considered as CV events. ${ }^{65}$ More recently, data related to the CV trial, within the TTrials, have become available. ${ }^{72}$ The study involved 138 subjects, and the primary outcome was to test the hypothesis that TRT would improve a surrogate CV outcome such as noncalcified coronary artery plaque volume, as determined by computed tomographic angiography. The result of this trial shows that TRT significantly increased coronary artery plaque progression during 12 months of treatment. ${ }^{72}$ Even in this case, several flaws should be recognized. A larger noncalcified plaque volume at enrollment was present in the placebo arm, when compared with that in the active group (317 vs $204 \mathrm{~mm}^{3}$ ). In addition, although the plaque volume showed a greater increase in the active arm, men enrolled in the T-groups still had a lower volume at the end point (232 vs $325 \mathrm{~mm}^{3}$ ). Moreover, at the end point, no differences between groups were observed in other important outcomes, such as coronary calcium score and the incidence of $\mathrm{CV}$ events among groups. ${ }^{72}$

As reported previously, along with the aforementioned RCTs described, 2 pharmacoepidemiological surveys contributed to the position supporting an increased CV risk related to TRT. In the first study, published in 2013, Vigen et al $^{66}$ retrospectively analyzed data including 8,709 American veterans (VA) who underwent coronary angiography between 2005 and 2011. The Authors reported that among men with hypogonadism (total $\mathrm{T}<10.4 \mathrm{nmol} / \mathrm{L}$ ), those who were prescribed TRT had an increased risk of major adverse cardiovascular events (MACEs) or death from any cause, when compared with those who did not use the same treatment. ${ }^{66}$ Soon after the publication of this study, Finkle et $\mathrm{al}^{67}$ reported similar data by analyzing a large Medicare insurance database including 55,593 subjects. In particular, they showed that TRT was associated with a 2-fold increased risk of heart attack among men aged 65 years and older, which was particularly evident in younger men with a preexisting history of heart disease. ${ }^{67}$ Both studies present important limitations. The main problem deals with the lack of information concerning $\mathrm{T}$ dosing and measurements during the follow-up. ${ }^{71,73}$ In addition, the comparison group included in the study by Finkle et $\mathrm{al}^{67}$ was composed of 167,000 subjects who were prescribed a PDE5i. The PDE5i has well-known cardio-protective effects, which should be considered in the data evaluation. ${ }^{74}$ Besides the latter studies, several other pharmacoepidemiological reports have investigated the possible relationship between TRT and CV risk. ${ }^{75}$ In a first qualitative analysis of these reports, Alexander et $\mathrm{al}^{76}$ concluded that all studies were characterized by a high clinical and methodological heterogeneity and by a very low quality. Interestingly, by using a meta-analytic method, we recently confirmed Alexander et $\mathrm{al}^{76}$ results on a high heterogeneity within these types of studies, but we were unable to confirm a risk of publication bias. In addition, our conclusion was that, when overall mortality and CV mortality and morbidity were considered, TRT resulted as being protective and not harmful. ${ }^{75}$ However, it is important to recognize that only a limited number of studies were available with overall poor quality, due to the lack of crucial information such as the level of T before and during TRT, the number of the blood samples drawn during treatment, the type of $\mathrm{T}$ preparations used, the dropout number, and the level of hematocrit. ${ }^{75}$

RCTs are usually considered the gold standard for testing the effect of a specific treatment. Until now. 9 systematic metaanalyses evaluating the effect of TRT on CV risk from placebo-controlled RCTs are available ${ }^{68,75-82}$ (Supplementary Table 1). The included amount of trials ranges from 19 to 75 , and the number of subjects considered ranges from 1,084 to 8,479. 7 meta-analyses $^{68,75-78,80-82}$ reported outcomes on aggregate $\mathrm{CV}$ events as their primary end point, whereas one ${ }^{79}$ investigated disaggregate events. In addition, disaggregate events were also analyzed by 6 studies, whereas 2 reported only aggregate analyses (Supplementary Table 1). Table 2 shows that only $\mathrm{Xu}$ et $\mathrm{al}^{68}$ reported an increased $\mathrm{CV}$ risk related to TRT. Conversely, no other meta-analyses found an increased CV risk related to TRT, when either aggregate or disaggregate CV events were considered (Table 2). Is important to recognize that, similar to what was observed in the TOM trial, ${ }^{65}$ the meta-analysis by $\mathrm{Xu}$ et $\mathrm{al}^{68}$ considered a broader definition of CV events, causing an artificial increase of the overall number of events. Some authors in their meta-analysis have suggested possible differences in $\mathrm{CV}$ risk when the different $\mathrm{T}$ preparations were considered. ${ }^{71}$ In particular, Borst et $\mathrm{al}^{47}$ suggested an increased $\mathrm{CV}$ risk related to the use of oral formulations, whereas Albert et $\mathrm{al}^{49}$ reported a possible increased risk using transdermal preparations, when the analysis was restricted to trials lasting less than 12 months. ${ }^{71}$ However, the largest and most updated meta-analysis did not confirm these data, suggesting a neutral effect when both aggregate or disaggregate events were considered, independently from the $\mathrm{T}$ preparation considered. ${ }^{71}$ Interestingly, our report showed that an increased $\mathrm{CV}$ risk was observed when $\mathrm{T}$ was prescribed at a higher dosage than those recommended by the available guidelines or when frail men were considered. ${ }^{75}$

\section{Erythrocytosis Risk}

Increased hematocrit has been inconsistently reported to be a risk factor for cardiovascular morbidity, mortality, and venous thromboembolism (VTE). The specific threshold related to an increased $\mathrm{CV}$ risk is still a matter of intense discussion. ${ }^{83}$ In particular, although a hematocrit $>54 \%$ is considered a well accepted indication for TRT withdrawal and phlebotomy, the standard level of hematocrit to be considered for starting TRT is conflicting. ${ }^{6,7,84}$ Much evidence has documented that TRT can increase hematocrit through different mechanisms, including direct (positive action on bone marrow erythroid progenitor 
Table 2. Odds ratio for aggregate or disaggregate cardiovascular (CV) events as derived from the available meta-analyses

\begin{tabular}{|c|c|c|c|c|c|c|c|c|c|}
\hline \multirow[b]{2}{*}{$\begin{array}{l}\text { Meta-analyses } \\
\text { considered }\end{array}$} & \multicolumn{9}{|l|}{ CV risk } \\
\hline & $\begin{array}{l}\text { Overall } \\
\text { CV events }\end{array}$ & MACE & AMI & $\begin{array}{l}\text { Acute coronary } \\
\text { syndrome }\end{array}$ & $\begin{array}{l}\text { Coronary by-pass } \\
\text { surgery }\end{array}$ & Stroke & Arrhythmias & $\begin{array}{l}\text { New heart } \\
\text { failure }\end{array}$ & $\begin{array}{l}\text { CV } \\
\text { mortality }\end{array}$ \\
\hline Calof et al, $2005^{77}$ & $1.22[0.53 ; 2.81]$ & - & $0.99[0.44 ; 2.26]$ & $\begin{array}{l}0.93 \\
{[0.39 ; 2.26]}\end{array}$ & $0.79[0.35 ; 1.79]$ & $0.86[0.38 ; 1.95]$ & $\begin{array}{l}1.22 \\
{[0.53 ; 2.81]}\end{array}$ & - & - \\
\hline Haddad et al, $2007^{78}$ & $1.82[0.78 ; 4.23]$ & - & $2.24[0.5,10.02]$ & - & & 3,703 & - & - & - \\
\hline $\begin{array}{l}\text { Fernández-Balsells } \\
\text { et al, } 2010^{79}\end{array}$ & - & - & - & - & $1.35[0.26,6.96]$ & - & $\begin{array}{l}3.00 \\
{[0.32 ; 27.94]}\end{array}$ & - & - \\
\hline Xu et al, $2013^{68}$ & $1.54[1.09 ; 2.18]$ & - & - & - & - & - & & - & $\begin{array}{l}1.42 \\
{[0.70 ; 2.89]}\end{array}$ \\
\hline Corona et al, $2014^{80}$ & 1.07 [0.69;1.65] & $\begin{array}{l}1.64 \\
{[0.25 ; 10.63]}\end{array}$ & $0.58[0.30,1.52]$ & $\begin{array}{l}0.92 \\
{[0.43 ; 1.97]}\end{array}$ & 2.09 [0.48;9.17] & $0.82[0.24,2.83]$ & $\begin{array}{l}1.15 \\
{[0.43 ; 3.05]}\end{array}$ & $1.64[0.25,10.63]$ & $\begin{array}{l}1.14 \\
{[0.49 ; 2.66]}\end{array}$ \\
\hline Borst et al, $2014^{81}$ & $1.28[0.76 ; 2.13]$ & - & - & - & - & - & - & - & - \\
\hline Albert et al, $2016^{82}$ & $1.10[0.86 ; 1.41]$ & - & - & - & - & - & - & - & - \\
\hline Alexander et al, $2016^{76}$ & - & - & $2.18[0.63,7.54]$ & - & - & $2.17[0.63 ; 7.54]$ & - & - & $\begin{array}{l}2.18 \\
{[0.63 ; 7.54]}\end{array}$ \\
\hline Corona et al, $2018^{75}$ & $1.02[0.74 ; 1.40]$ & $\begin{array}{l}0.97 \\
{[0.64 ; 1.46]}\end{array}$ & $0.84[0.43 ; 1.65]$ & $\begin{array}{l}0.79 \\
{[0.44 ; 142]}\end{array}$ & - & $0.99[0.44 ; 2.24]$ & - & $0.81[0.27 ; 2.42]$ & $\begin{array}{l}1.12 \\
{[0.51 ; 2.48]}\end{array}$ \\
\hline \multicolumn{10}{|l|}{ Erythrocytosis risk } \\
\hline Calof et al, $2005^{77}$ & \multicolumn{4}{|c|}{ Level of risk NA } & \multicolumn{3}{|l|}{ Overall population } & \multicolumn{2}{|l|}{$3.69[1.82 ; 7.51]$} \\
\hline $\begin{array}{l}\text { Fernandez-Balsells } \\
\text { et al, } 2010^{79}\end{array}$ & \multicolumn{4}{|c|}{ Level of risk $>50 \%$} & \multicolumn{3}{|l|}{ Overall population } & \multicolumn{2}{|l|}{$3.15[1.56 ; 6.35]$} \\
\hline \multirow[t]{2}{*}{ Corona et al, $2015^{85}$} & \multirow{2}{*}{\multicolumn{4}{|c|}{ Level of risk $>52 \%$}} & \multicolumn{3}{|c|}{ Overall population } & \multicolumn{2}{|l|}{$3.62[1.86 ; 7.05]$} \\
\hline & & & & & \multicolumn{3}{|c|}{$\mathrm{T}<12 \mathrm{nM}$ and transdermal preparations } & \multicolumn{2}{|l|}{$4.89[0.83 ; 28.91]$} \\
\hline \multirow{4}{*}{$\begin{array}{l}\text { Corona et al, } \\
\text { (present study) }\end{array}$} & \multicolumn{4}{|c|}{ Level of risk $>52 \%$} & \multicolumn{3}{|c|}{ Overall population } & \multicolumn{2}{|l|}{$4.56[w 2.64 ; 7.89]$} \\
\hline & & & & & \multicolumn{3}{|c|}{$\mathrm{T}<12 \mathrm{nM}$ and transdermal preparations } & \multicolumn{2}{|l|}{$2.38[0.26 ; 21.62]$} \\
\hline & & & & & \multicolumn{3}{|c|}{$\mathrm{T}<12 \mathrm{nM}$ and long acting TU } & \multicolumn{2}{|l|}{$2.23[0.68 ; 7.36]$} \\
\hline & & & & & $\mathrm{T}<12 \mathrm{nM}$ and olc & T ester preparatio & & $8.03[3.27 ; 19.72]$ & \\
\hline Venous thromboembolis & m risk & & & & & & & & \\
\hline Xu et al, $2015^{87}$ & Level of risk & & & & & & & $5.94[1.00 ; 35.30]$ & \\
\hline Corona et al, $2015^{85}$ & Level of risk & & & & & & & $1.96[0.75 ; 5.17]$ & \\
\hline Houghton & Level of risk & & & & $\mathrm{RCTs}$ & & & $2.05[0.78 ; 5.39]$ & \\
\hline & Observational ca: & se control stuc & dies & & & & & $1.34[0.78 ; 2.28]$ & \\
\hline & Cohort studies & & & & & & & $4.89[0.83 ; 28.91]$ & \\
\hline Corona et $\mathrm{al}{ }^{75}$ & Level of risk $>5$ & $2 \%$ & & & Overall population & & & $4.56[2.64 ; 7.89]$ & \\
\hline & & & & & $\mathrm{T}<12 \mathrm{nM}$ and tra & insdermal preparati & ions & $2.38[0.26 ; 21.62]$ & \\
\hline & & & & & $\mathrm{T}<12 \mathrm{nM}$ and lor & g-acting TU & & $2.23[0.68 ; 7.36]$ & \\
\hline & & & & & $\mathrm{T}<12 \mathrm{nM}$ and olc & T ester preparatio & & $8.03[3.27 ; 19.72]$ & \\
\hline
\end{tabular}

$\mathrm{AMI}=$ Acute myocardial infarction; $\mathrm{CV}=$ cardiovascular; MACE = major adverse cardiovascular event; $\mathrm{NA}=$ not available; RCTs = randomized controlled trials; $\mathrm{T}=$ testosterone. 


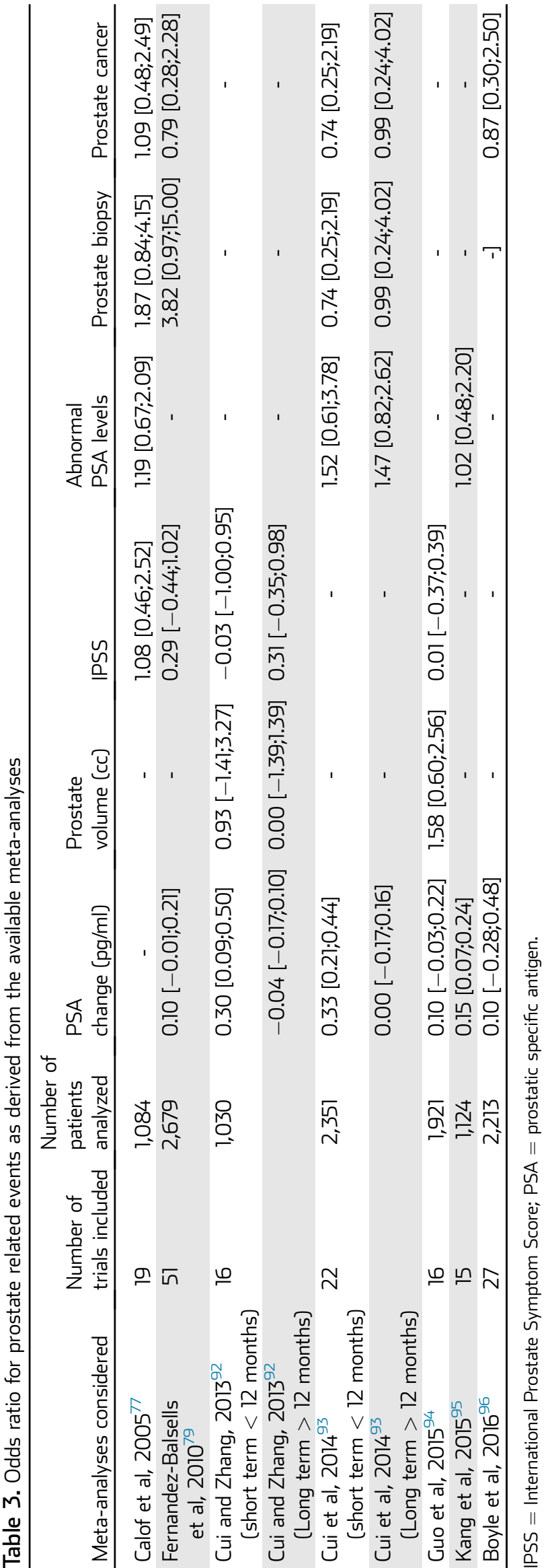

cells) and indirect (stimulation of endogenous erythropoietin or inhibition of hepcidin, both involved in the iron pathway regulation) ones. ${ }^{83}$ Accordingly, available meta-analyses, which analyzed the risk of erythrocytosis due to TRT, in comparison with placebo, showed that T-treated subjects had a 3- to 4-fold increased risk of developing an elevated hematocrit ${ }^{75,77,79,85}$ (Table 2). Old short-term parenteral $\mathrm{T}$ preparations have been reported to produce the highest risk of erythrocytosis, due to the high fluctuation of $\mathrm{T}$ levels. ${ }^{83}$ Accordingly, we previously reported that, when the analysis is limited to those studies applying transdermal preparations in the active arm and enrolling only subjects with hypogonadism $(\mathrm{T}<12 \mathrm{nM})$, the risk of elevated hematocrit is not confirmed ${ }^{85}$ (Table 2). By using the data from the most updated meta-analysis on $\mathrm{CV}$ risk, ${ }^{75}$ we here confirm that when using either transdermal preparations or long-acting TU in subjects with hypogonadism $(\mathrm{T}<12 \mathrm{nM})$, there is no increase in the risk of erythrocytosis ${ }^{85,86}$ (see also Table 2). This was not the case when older $T$ ester preparations were considered, as previously reported (Table 2; 86).

\section{Venous Thromboembolism Risk}

Only few placebo-controlled RCTs have investigated a possible association between VTE risk and TRT. In 2015, Xu et $\mathrm{al},{ }^{87}$ by analyzing the data including only 3 RCTs enrolling 516 subjects, reported that TRT significantly increased VTE (Table 2). These data were not confirmed by our group when 6 trials were considered, enrolling 1217 and 1,166 patients treated with TRT or placebo, respectively (88; Table 2 ). In line with this view, Houghton et $\mathrm{al}^{88}$ by meta-analyzing placebo-controlled RCTs, including 2236 patients, and 5 observational studies, including 1,249,640 subjects, concluded that current evidence does not support an association between $\mathrm{T}$ use and VTE in men (Table 2). Accordingly, it has been reported that TRT-related VTE events were frequently associated with an undiagnosed thrombophilia-hypofibrinolysis status, suggesting the relevance of an accurate medical history before starting TRT. ${ }^{70}$

\section{Prostate}

The historical view that $\mathrm{T}$ is detrimental and harmful for prostate health is nowadays considered not to be evidence based. Several data have clarified that androgens not only are involved in the stimulation of prostate cell proliferation but also play a crucial role in the regulation of prostate cell differentiation. ${ }^{89,90}$ As support of the latter evidence, epidemiological data have shown that lower (ie, lower effect on prostate cell differentiation) rather than higher $\mathrm{T}$ circulating levels are associated with less differentiated forms of PC. ${ }^{89,90}$ In addition, it is important to recognize that in accordance with Morgentaler and Traish's "saturation hypothesis," during physiological conditions, circulating androgens saturate the human prostate androgen receptors making the prostate rather insensitive to further $\mathrm{T}$ increase. ${ }^{91}$ In line with their hypothesis, both in vitro and clinical evidence have documented that prostate cell proliferation is observed only 
at low $\mathrm{T}$ concentration levels but disappears when $\mathrm{T}$ levels reach the eugonadal range. ${ }^{89,90}$

Several meta-analyses have been published specifically investigating the role of TRT on prostate safety (see also Table 3). ${ }^{77,79,92-96}$ The number of trials considered ranged from 4 to 26 , including 1,084 to 5,464 subjects. In line with what has previously been reported, TRT induced only a short-term increase in prostatic specific antigen levels $(95-65)$ or in prostate volume $^{94}$ (Table 3). Conversely, when studies lasting more than 12 months were considered, no risk of PC or prostate-related events were reported (Table 3). Data from the TTrials confirm these observations, as no difference in prostate-related events or PC was observed when treated men were compared with those enrolled in the placebo group at the end point. ${ }^{10}$

Similar data can be derived from registry studies. Data from the Registry of Hypogonadism in Men,a multinational registry of men with hypogonadism including 999 subjects (mean age $59.1 \pm 10.5$ years) with a follow-up of 3 years, did not document any difference in prostatic specific antigen levels, total International Prostate Symptom Score (IPSS) (including IPSS obstructive subscale), or PC in subjects undergoing TRT, when compared with those untreated. ${ }^{97}$ Interestingly, the same study also indicated that TRT resulted in even lower IPSS irritative subscale scores, when compared with untreated men. ${ }^{96}$ Similar results were derived from another Italian registry (SIAMO-NOI), which collected data from 432 men with hypogonadism in 15 centers. ${ }^{98}$ In addition, data derived from either animal models or clinical observations have documented that HG is characterized by an increased prostate inflammation, particularly evident in patients with obesity and metabolic disorders, which can contribute to benign prostatic hyperplasia-related symptoms and can be improved by TRT, explaining, at least partially, the aforementioned observations. Accordingly, preliminary data from a placebo-controlled RCT, involving 120 men with MetS and benign prostatic hyperplasia, showed that TRT produced a moderate improvement in lower urinary tract symptoms, associated with a significant decline in prostate artery flow velocity and acceleration, as assessed by transrectal color Doppler ultrasound, and with a decrease, in the prostatic tissue, of the expression of some inflammation-related genes, such as cyclooxygenase-2, monocyte chemoattractant protein-1, and related orphan receptor gamma-t. ${ }^{99}$

A final point to be discussed is related to the effect of TRT in men treated for PC. A limited number of studies have investigated the role of TRT in men curatively treated after surgery with radiotherapy for PC. Recently, Telling et $\mathrm{al}^{100}$ collected and meta-analyzed information derived from 13 studies including 608 patients, of which 109 had a history of high-risk PC. The follow-up ranged from one to 189.3 months, and the type of $\mathrm{T}$ preparations used differed among studies. The authors concluded that TRT did not increase the risk of biochemical recurrence, but the available evidence is very low, limiting, therefore, the data interpretation. ${ }^{100}$

\section{CONCLUSIONS}

Data derived from RCT and observational studies have clearly documented that TRT can improve erectile function, libido, and other aspects of sexual activities in men with hypogonadism (total $\mathrm{T}<12$ nmoles/L). The effect is inversely related to the baseline $\mathrm{T}$ levels and is lower in patients with higher numbers of associated morbidities. Although several data have documented that lower $\mathrm{T}$ levels are associated with a worse metabolic profile and a higher CV risk, ${ }^{101}$ the specific contribution of TRT in improving these aspects remains conflicting. In fact, whether the low $\mathrm{T}$ level in men with increased $\mathrm{CV}$ risk plays a direct role in the risk stratification or it represents an adaptive mechanism to a compromised health status has still not been completely clarified. ${ }^{37}$ Hence, based on the available evidence, TRT should not consider a viable alternative medication to improve metabolic profile in men with T2DM or MetS or to reduce the risk of bone fractures in men with osteoporosis. Similar considerations should be done for mood, cognition, and mobility.

When HG is correctly diagnosed and $\mathrm{T}$ is administered as per the recommended dosage, no CV risk is derived. However, it is important to recognize that the duration of the available trials is too short (lower than 3 years) to draw conclusions. In fact, limited information on possible long-term effects of TRT on CV risk is available. An industry-supported multicenter RCT is underway to investigate the long-term CV risk of TRT (clinicaltrials.gov: NCT03518034).

Similarly, the evidence published so far does not indicate any prostate risk related to TRT. However, none of the studies were sufficiently powered to exclude adverse event risks in the longer term. Similarly, preliminary positive data of TRT in IPSS improvement must be confirmed in well-designed long-term trials. In particular, limited information is available in men with severe lower urinary tract symptoms (ie, IPSS $>19$ ) because they are usually excluded from RCTs.

Corresponding Author: Giovanni Corona, MD, PhD, Endocrinology Unit, Medical Department, Azienda Usl Bologna Maggiore-Bellaria Hospital, Largo Nigrisoli, 2, 40133 Bologna, Italy. Tel: +39-051-6478060; Fax: +39-051-6478058; E-mail: jocorona@libero.it

Conflict of Interest: The authors report no conflicts of interest.

Funding: None.

\section{STATEMENT OF AUTHORSHIP}

\section{Category 1}

(a) Conception and Design

Giovanni Corona; Mario Maggi

(b) Acquisition of Data

Giovanni Corona

(c) Analysis and Interpretation of Data

Giovanni Corona; Mario Maggi 


\section{Category 2}

(a) Drafting the Article Giovanni Corona; Mario Maggi; Luiz Otavio Torres

(b) Revising It for Intellectual Content Giovanni Corona; Mario Maggi; Luiz Otavio Torres

\section{Category 3}

(a) Final Approval of the Completed Article Giovanni Corona; Mario Maggi

\section{REFERENCES}

1. Huhtaniemi I. Late-onset hypogonadism: current concepts and controversies of pathogenesis, diagnosis and treatment. Asian J Androl 2014;16:192-202.

2. Wu FC, Tajar A, Pye SR, et al. Hypothalamic-pituitary-testicular axis disruptions in older men are differentially linked to age and modifiable risk factors: the European Male Aging Study. J Clin Endocrinol Metab 2008;93:2737-2745.

3. Tajar A, Forti G, O'Neill TW, et al. Characteristics of secondary, primary, and compensated hypogonadism in aging men: evidence from the European Male Ageing Study. J Clin Endocrinol Metab 2010;95:1810-1818.

4. Mohr BA, Guay AT, O'Donnell AB, et al. Normal, bound and nonbound testosterone levels in normally ageing men: results from the Massachusetts Male Ageing Study. Clin Endocrinol (Oxf) 2005;62:64-73.

5. Grossmann M, Matsumoto AM. A perspective on middleaged and older men with functional hypogonadism: focus on holistic management. J Clin Endocrinol Metab 2017; 102:1067-1075.

6. Bhasin S, Brito JP, Cunningham GR, et al. Testosterone therapy in men with hypogonadism: an Endocrine Society clinical practice guideline. J Clin Endocrinol Metab 2018; 103:1715-1744.

7. Yeap BB, Grossmann M, McLachlan RI, et al. Endocrine Society of Australia position statement on male hypogonadism (part 1): assessment and indications for testosterone therapy. Med J Aust 2016;205:173-178.

8. FDA Drug Safety Communication FDA cautions about using $T$ products for low $T$ due to aging requires labeling change to inform of possible increased risk of heart attack and stroke with use; US Food and Drug Administration website. Available at: http://www.fda.gov/Drugs/DrugSafety/ucm436259.htmfor HumanMedicalProducts/ucm402054.htm. Accessed February 11, 2019. Published March 3, 2015.

9. Summary safety review-testosterone replacement productcardiovascular risk; Health Canada website. Available at: http://www.hc-sc.gc.ca/dhp-mps/medeff/reviews-examens/ testosterone-eng.php. Accessed February 11, 2019. Published July 15, 2014.

10. Snyder PJ, Bhasin S, Cunningham GR, et al. Lessons from the testosterone trials. Endocr Rev 2018;39:369-386.

11. Nieschlag E, Nieschlag S. Testosterone deficiency: a historical perspective. Asian J Androl 2014;16:161-168.
12. Jasuja GK, Bhasin S, Rose AJ. Patterns of testosterone prescription overuse. Curr Opin Endocrinol Diabetes Obes 2017; 24:240-245.

13. Corona G, Maggi M. Deciding which testosterone therapy to prescribe. J Sex Med 2018;15:619-621.

14. Baillargeon J, Urban RJ, Ottenbacher KJ, et al. Trends in androgen prescribing in the United States, 2001 to 2011. JAMA Intern Med 2013;173:1465-1466.

15. Muram D, Zhang X, Cui Z, et al. Use of hormone testing for the diagnosis and evaluation of male hypogonadism and monitoring of testosterone therapy: application of hormone testing guideline recommendations in clinical practice. J Sex Med 2015;12:1886-1894.

16. GK1 Jasuja, Bhasin S, ReismanJl, et al. Ascertainment of testosterone prescribing practices in the VA. Med Care 2015; 53:746-752.

17. Corona G, Isidori AM, Aversa A, et al. Endocrinologic control of men's sexual desire and arousal/erection. J Sex Med 2016; 13:317-337.

18. Rastrelli G, Corona G, Maggi M. Testosterone and sexual function in men. Maturitas 2018;112:46-52.

19. Rastrelli G, Guaraldi F, Reismann Y, et al. Testosterone replacement therapy for sexual symptoms. Sex Med Rev 2019. https://doi.org/10.1016/j.sxmr.2018.11.005; E-pub ahead of print.

20. Corona G, Rastrelli G, Morgentaler A, et al. Meta-analysis of results of testosterone therapy on sexual function based on International Index of Erectile Function Scores. Eur Urol 2017; 72:1000-1011.

21. Rosen RC, Allen KR, Ni X, et al. Minimal clinically important differences in the erectile function domain of the International Index of Erectile Function Scale. Eur Urol 2011;60:1010-1016.

22. Corona G, Isidori AM, Buvat J, et al. Testosterone supplementation and sexual function: a meta-analysis study. J Sex Med 2014;11:1577-1592.

23. Maggi M, Heiselman D, Knorr J, et al. Impact of Testosterone solution $2 \%$ on ejaculatory dysfunction in hypogonadal men. J Sex Med 2016;13:1220-1226.

24. Grossmann M. Hypogonadism and male obesity: focus on unresolved questions. Clin Endocrinol (Oxf) 2018;89:11-21.

25. Lotti F, Rastrelli G, Maseroli E, et al. Impact of metabolically healthy obesity in patients with andrological problems. J Sex Med 2019;16:821-832.

26. Camacho EM, Huhtaniemi IT, O'Neill TW, et al. Age-associated changes in hypothalamic-pituitary-testicular function in middle-aged and older men are modified by weight change and lifestyle factors: longitudinal results from the European Male Ageing Study. Eur J Endocrinol 2013;168:445-455.

27. Rastrelli G, Carter EL, Ahern T, et al. Development of and recovery from secondary hypogonadism in aging men: prospective results from the EMAS. J Clin Endocrinol Metab 2015;100:3172-3182.

28. Morelli A, Filippi S, Comeglio P, et al. Physical activity counteracts metabolic syndrome-induced hypogonadotropic 
hypogonadism and erectile dysfunction in the rabbit. Am J Physiol Endocrinol Metab 2019;316:E519-E535.

29. Ng Tang Fui M, Hoermann R, Zajac JD, et al. The effects of testosterone on body composition in obese men are not sustained after cessation of testosterone treatment. Clin Endocrinol (Oxf) 2017;87:336-343.

30. Corona G, Giagulli VA, Maseroli E, et al. Therapy of endocrine disease: testosterone supplementation and body composition: results from a meta-analysis study. Eur J Endocrinol 2016;174:R99-R116.

31. Corona G, Giagulli VA, Maseroli E, et al. Testosterone supplementation and body composition: results from a metaanalysis of observational studies. J Endocrinol Invest 2016; 39:967-981.

32. Corona G, Rastrelli G, Morelli A, et al. Treatment of functional hypogonadism besides pharmacological substitution. World J Mens Health 2019. https://doi.org/10.5534/wjmh.190061; E-pub ahead of print.

33. Corona G, Vignozzi L, Sforza A, et al. Obesity and lateonsethypogonadism. Mol Cell Endocrinol 2015;418 Pt 2:120-133.

34. Jones $\mathrm{TH}$, Arver S, Behre HM, et al. Testosterone replacement in hypogonadal men with type 2 diabetes and/ or metabolic syndrome (the TIMES2 study). Diabetes Care 2011;34:828-837.

35. Hackett G, Cole N, Bhartia M, et al. Testosterone replacement therapy improves metabolic parameters in hypogonadal men with type 2 diabetes but not in men with coexisting depression: the BLAST study. J Sex Med 2014;11:840-856.

36. Gianatti EJ, Dupuis P, Hoermann R, et al. Effect of testosterone treatment on constitutional and sexual symptoms in men with type 2 diabetes in a randomized, placebo-controlled clinical trial. J Clin Endocrinol Metab 2014;99:3821-3828.

37. Corona G, Maseroli E, Rastrelli G, et al. Is late-onset hypogonadotropic hypogonadism a specific age-dependent disease, or merely an epiphenomenon caused by accumulating disease-burden? Minerva Endocrinol 2016;41:196-210.

38. Haider A, Saad F, Doros G, et al. Hypogonadal obese men with and without diabetes mellitus type 2 lose weight and show improvement in cardiovascular risk factors when treated with testosterone: an observational study. Obes Res Clin Pract 2014;8:e339-e349.

39. Francomano D, Lenzi A, Aversa A. Effects of five-year treatment with testosterone undecanoate on metabolic and hormonal parameters in ageing men with metabolic syndrome. Int J Endocrinol 2014,2014:527470.

40. Zitzmann M, Mattern A, Hanisch J, et al. IPASS: a study on the tolerability and effectiveness of injectable testosterone undecanoate for the treatment of male hypogonadism in a worldwide sample of 1,438 men. J Sex Med 2013;10:579588.

41. Traish AM, Haider A, Doros G, et al. Long-term testosterone: therapy in hypogonadal men ameliorates elements of the metabolic syndrome: an observational, long-term registry study. Int J Clin Pract 2014;68:314-329.
42. Rochira $V$, Antonio L, Vanderschueren D. EAA clinical guideline on management of bone health in the andrological outpatient clinic. Andrology 2018;6:272-285.

43. Isidori AM, Giannetta E, Greco EA, et al. Effects of testosterone on body composition, bone metabolism and serum lipid profile in middle-aged men: a meta-analysis. Clin Endocrinol (Oxf) 2005;63:280-293.

44. Tracz MJ, Sideras K, Boloña ER, et al. Testosterone use in men and its effects on bone health. A systematic review and metaanalysis of randomized placebo-controlled trials. J Clin Endocrinol Metab 2006;91:2011-2016.

45. Smith JB, Rosen J, Colbert A. Low serum testosterone in outpatient psychiatry clinics: addressing challenges to the screening and treatment of hypogonadism. Sex Med Rev 2018;6:69-76.

46. Walther A, Breidenstein J, Miller R. Association of testosterone treatment with alleviation of depressive symptoms in men: a systematic review and meta-analysis. JAMA Psychiatry 2019;76:31-40.

47. McGinty HL, Phillips KM, Jim HS, et al. Cognitive functioning in men receiving androgen deprivation therapy for prostate cancer: a systematic review and meta-analysis. Support Care Cancer 2014;22:2271-2280.

48. Lv W, Du N, Liu Y, et al. Low testosterone level and risk of Alzheimer's disease in the elderly men: a systematic review and meta-analysis. Mol Neurobiol 2015 Jul 8; E-pub ahead of print.

49. Nieschlag E, Vorona E. Mechanisms in endocrinology: Medical consequences of doping with anabolic androgenic steroids: effects on reproductive functions. Eur J Endocrinol 2015; 173:R47-R58.

50. Steeves JA, Fitzhugh EC, Bradwin G, et al. Cross-sectional association between physical activity and serum testosterone levels in US men: results from NHANES 1999-2004. Andrology 2016;4:465-472.

51. Rochira V, Zirilli L, Orlando G, et al. Premature decline of serum total testosterone in HIV-infected men in the HAARTera. PLoS One 2011;6:e28512.

52. Johns K, Beddall MJ, Corrin RC. Anabolic steroids for the treatment of weight loss in HIV-infected individuals. Cochrane Database Syst Rev 2005;4:CD005483.

53. Corona G, Rastrelli G, Maggi M. Diagnosis and treatment of late-onset hypogonadism: systematic review and metaanalysis of TRT outcomes. Best Pract Res Clin Endocrinol Metab 2013;27:557-579.

54. Zhou T, Hu ZY, Zhang HP, et al. Effects of Testosterone supplementation on body composition in HIV patients: a meta-analysis of double-blinded randomized controlled trials. Curr Med Sci 2018;38:191-198.

55. Coluzzi F, Billeci D, Maggi M, et al. Testosterone deficiency in non-cancer opioid-treated patients. J Endocrinol Invest 2018;41:1377-1388.

56. Basaria S, Travison TG, Alford D, et al. Effects of testosterone replacement in men with opioid-induced androgen deficiency: a randomized controlled trial. Pain 2015;156:280-288. 
57. Crawford BA, Liu PY, Kean MT, et al. Randomized placebocontrolled trial of androgen effects on muscle and bone in men requiring long-term systemic glucocorticoid treatment. J Clin Endocrinol Metab 2003;88:3167-3176.

58. Reid IR, Wattie DJ, Evans MC, et al. Testosterone therapy in glucocorticoid-treated men. Arch Intern Med 1996; 156:1173-1177.

59. Atlantis E, Fahey P, Cochrane B, et al. Endogenous testosterone level and testosterone supplementation therapy in chronic obstructive pulmonary disease (COPD): a systematic review and meta-analysis. BMJ Open 2013;3.

60. Bao $Y$, Johansen KL. Diagnosis and treatment of low testosterone among patients with end-stage renal disease. Semin Dial 2015;28:259-265.

61. Vignozzi L, Cellai I, Santi R, et al. Antiinflammatory effect of androgen receptor activation in human benign prostatic hyperplasia cells. J Endocrinol 2012;214:31-43.

62. Francomano D, Ilacqua A, Bruzziches R, et al. Effects of 5year treatment with testosterone undecanoate on lower urinary tract symptoms in obese men with hypogonadism and metabolic syndrome. Urology 2014;83:167-173.

63. Nasser M, Haider A, Saad F, et al. Testosterone therapy in men with Crohn's disease improves the clinical course of the disease: data from long-term observational registry study. Horm Mol Biol Clin Investig 2015;22:111-117.

64. Haider A, Kurtz W, Giltay EJ, et al. Administration of testosterone to elderly hypogonadal men with Crohn's disease improves their Crohn's disease activity index: a pilot study. Horm Mol Biol Clin Investig 2010;2:287-292.

65. Basaria S, Coviello AD, Travison TG, et al. Adverse events associated with testosterone administration. N Engl J Med 2010;363:109-122.

66. Vigen $\mathrm{R}$, O'Donnell $\mathrm{Cl}$, Barón $\mathrm{AE}$, et al. Association of testosterone therapy with mortality, myocardial infarction, and stroke in men with low testosterone levels. JAMA 2013; 310:1829-1836.

67. Finkle WD, Greenland S, Ridgeway GK, et al. Increased risk of non-fatal myocardial infarction following testosterone therapy prescription in men. PLoS One 2014;9:e85805.

68. Xu L, Freeman G, Cowling BJ, et al. Testosterone therapy and cardiovascular events among men: a systematic review and meta-analysis of placebo-controlled randomized trials. BMC Med 2013;11:108.

69. Corona G, Vignozzi L, Sforza A, et al. Risks and benefits of late onset hypogonadism treatment: an expert opinion. World J Mens Health 2013;31:103-125.

70. Corona G, Dicuio M, Rastrelli G, et al. Testosterone treatment and cardiovascular and venous thromboembolism risk: what is 'new'? J Investig Med 2017;65:964-973.

71. Corona G, Rastrelli G, Reisman Y, et al. The safety of available treatments of male hypogonadism in organic and functional hypogonadism. Expert Opin Drug Saf 2018;17:277-292.

72. Budoff MJ, Ellenberg SS, Lewis CE, et al. Testosterone treatment and coronary artery plaque volume in older men with low testosterone. JAMA 2017;317:708-716.
73. Corona G, Rastrelli G, Guaraldi F, et al. An update on heart disease risk associated with testosterone boosting medications. Expert Opin Drug Saf 2019;18:321-332.

74. Santi D, Giannetta E, Isidori AM, et al. Therapy of endocrine disease. Effects of chronic use of phosphodiesterase inhibitors on endothelial markers in type 2 diabetes mellitus: a meta-analysis. Eur J Endocrinol 2015;172:R103-R114.

75. Corona G, Rastrelli G, Di Pasquale G, et al. Testosterone and cardiovascular risk: meta-analysis of interventional studies. J Sex Med 2018;15:820-838.

76. Alexander GC, lyer G, Lucas E, et al. cardiovascular risks of exogenous testosterone use among men a systematic review and meta-analysis. Am J Med 2017;130:293-305.

77. Calof OM, Singh AB, Lee ML, et al. Adverse events associated with testosterone replacement in middle-aged and older men: a meta-analysis of randomized, placebo-controlled trials. J Gerontol A Biol Sci Med Sci 2005;60:1451-1457.

78. Haddad RM, Kennedy CC, Caples SM, et al. Testosterone and cardiovascular risk in men: a systematic review and metaanalysis of randomized placebo-controlled trials. Mayo Clin Proc 2007;82:29-39.

79. Fernández-Balsells MM, Murad MH, Lane M, et al. Clinical review 1: adverse effects of testosterone therapy in adult men: a systematic review and meta-analysis. J Clin Endocrinol Metab 2010;95:2560-2575.

80. Corona G, Maseroli E, Rastrelli G, et al. Cardiovascular risk associated with testosterone boosting medications: a systematic review and meta-analysis. Expert Opin Drug Saf 2014;13:1327-1351.

81. Borst SE, Shuster JJ, Zou B, et al. Cardiovascular risks and elevation of serum DHT vary by route of testosterone administration: a systematic review and meta-analysis. BMC Med 2014;12:211.

82. Albert SG, Morley JE. Testosterone therapy, association with age, initiation and mode of therapy with cardiovascular events: a systematic review. Clin Endocrinol (Oxf) 2016; 85:436-443.

83. Ohlander SJ, Varghese B, Pastuszak AW. Erythrocytosis Following Testosterone Therapy. Sex Med Rev 2018; 6:77-85.

84. Khera M, Adaikan G, Buvat J, et al. Diagnosis and treatment of testosterone deficiency: recommendations from the Fourth International Consultation for Sexual Medicine (ICSM 2015). J Sex Med 2016;13:1787-1804.

85. Corona G, Rastrelli G, Maseroli E, et al. testosterone replacement therapy and cardiovascular risk: a review. World J Mens Health 2015;33:130-142.

86. Corona G, Maseroli E, Maggi M. Injectable testosterone undecanoate for the treatment of hypogonadism. Expert Opin Pharmacother 2014;15:1903-1926.

87. Xu L, Schooling CM. Differential risks in men and women for first and recurrent venous thrombosis: the role of genes and environment: comment. J Thromb Haemost 2015;13:884.

88. Houghton DE, Alsawas M, Barrioneuvo P, et al. Testosterone therapy and venous thromboembolism: A systematic review and meta-analysis. Thromb Res 2018;172:94-103. 
89. Corona G, Baldi E, Maggi M. Androgen regulation of prostate cancer: where are we now? J Endocrinol Invest 2011;34:232-243.

90. Davidson E, Morgentaler A. Testosterone therapy and prostate cancer. Urol Clin North Am 2016;43:209-216.

91. Morgentaler A, Traish AM. Shifting the paradigm of testosterone and prostate cancer: the saturation model and the limits of androgen-dependent growth. Eur Urol 2009; 55:310-320.

92. Cui $Y$, Zhang Y. The effect of androgen-replacement therapy on prostate growth: a systematic review and meta-analysis. Eur Urol 2013;64:811-822.

93. Cui $Y$, Zong $H$, Yan $H$, et al. The effect of testosterone replacement therapy on prostate cancer: a systematic review and meta-analysis. Prostate Cancer Prostatic Dis 2014; 17:132-143.

94. Guo C, Gu W, Liu M, et al. Efficacy and safety of testosterone replacement therapy in men with hypogonadism: a metaanalysis study of placebo-controlled trials. Exp Ther Med 2016;11:853-863.

95. Kang DY, Li HJ. The effect of testosterone replacement therapy on prostate-specific antigen (PSA) levels in men being treated for hypogonadism: a systematic review and meta-analysis. Medicine (Baltimore) 2015;94:e410.

96. Boyle P, Koechlin A, Bota M, et al. Endogenous and exogenous testosterone and the risk of prostate cancer and increased prostate-specific antigen (PSA) level: a metaanalysis. BJU Int 2016;118:731-741.

97. Debruyne FM, Behre HM, Roehrborn CG, et al. Testosterone treatment is not associated with increased risk of prostate cancer or worsening of lower urinary tract symptoms: prostate health outcomes in the registry of hypogonadism in men. BJU Int 2017;119:216-224.

98. Rastrelli G, Giovannini L, Calogero AE, et al. Predictors and clinical consequences of starting androgen therapy in men with low testosterone: results from the SIAMO-NOI registry. J Endocrinol Invest 2016;39:695-708.

99. Rastrelli G, Cipriani S, Lotti F, et al. Testosterone replacement therapy is able to reduce prostate inflammation in men with $\mathrm{BPH}$, metabolic syndrome and hypogonadism: preliminary results from a randomized placebo-controlled clinical trial. J Sex Med 2018;15:S160.

100. Teeling F, Raison N, Shabbir M, et al. Testosterone therapy for high-risk prostate cancer survivors: a systematic review and meta-analysis. Urology 2019;126:16-23.

101. Corona G, Rastrelli G, Di Pasquale G, et al. Endogenous testosterone levels and cardiovascular risk: meta-analysis of observational studies. J Sex Med 2018b;15:1260-1271.

\section{SUPPLEMENTARY DATA}

Supplementary data related to this article can be found at https://doi.org/10.1016/j.jsxm.2019.11.270. 